\title{
Booklet Return Not Requested
}

National Cancer Institute

\section{Source}

National Cancer Institute. Booklet Return Not Requested. NCI Thesaurus. Code C106469.

The return of a booklet is or was not requested. 